
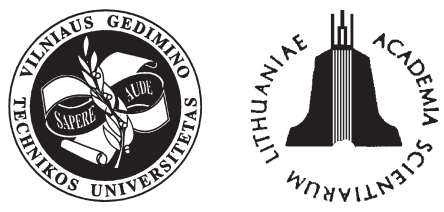

ISSN 1648-4142 TRANSPORT

www.transport.vtu.lt

TRANSPORT - 2005, Vol XX, No 4, 129-134

\title{
CARGO PIERS IN DREDGING HARBOUR WATERS
}

\author{
Antanas Kudzys ${ }^{1}$, Laimutis Jonas Vaicekauskas ${ }^{2}$ \\ ${ }^{1}$ Institute of Architecture and Construction, Kaunas University of Technology, \\ Tunelio g.60, 44405 Kaunas, Lithuania.E-mail: asi@asi.lt \\ ${ }^{2}$ Civil Engineering Department, Klaipèda University, Bijūnų g. 17, 91225 Klaipèda, \\ Lithuania.E-mail:Vaice@balticum-tv.lt
}

Received 2005-01-17; accepted 2005-05-25

\begin{abstract}
Structural behaviour and reliability peculiarities of cargo piers in deepened harbour waters are discussed. Deterministic and probabilistic reliability assessment methods for permeable cargo piers exposed to lateral berthing actions and gravity permanent and variable loads are analysed. Some new methodological approaches to probabilistic reliability assessment of existing cargo piers are presented. The survival probability assessment of pier piles is based on their irreversible serviceability and safety margins. The numerical example illustrates the virtue of probability-based approaches and methods of design practice of cargo piers.
\end{abstract}

Keywords: cargo piers, dredging waters, bearthing actions, pier piles, structural reliability, irreversible serviceability.

\section{Introduction}

The dredging of harbour waters is very actual for the seaports of Baltic countries. This actuality is closely related to sea-going cargo vessels of increased displacement (tonnage). However, new harbour situations lead to increased berthing impacts of vessels and cargo loads and the same, to overloading of existing cargo piers by lateral (horizontal) and gravity forces. At the same the load-carrying capacity of these piers is related to new structural and geotechnical conditions and must be adequate for the required long period of time.

Permeable cargo piers (Fig 1) are mostly composed of plain or ribbed reinforced concrete decks supported by concrete, steel or composite pipe piles. Several failure functions exist for pier piles because they may fail in different ways and because of different action effects caused by gravity and lateral actions. Therefore, after deepening of harbour waters the values not only of dimensions, material and soil properties of existing piers, but also of intensities and uncertainties of harbour actions should be verified by structural inspection to an adequate extent. Besides, quality statistical information data on unfavourable random gravity and lateral actions may be treated as an effective measure in the revised reliability assessment and prediction of existing harbour structures [1].

According to the general format of the design codes [2-4] the appropriate reliability degrees of harbour structures may be assessed by the deterministic and probability-based methods using partial safety factors and survival or failure probabilities, respectively. The results of the probabilistic analysis of cargo piers and other harbour work may appear generally discordant with those obtained by the deterministic approach. Therefore, the attempts are

a)

$\mathrm{A}-\mathrm{A}$
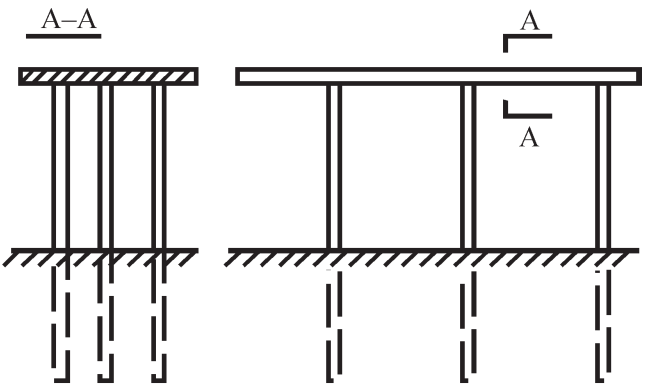

b)

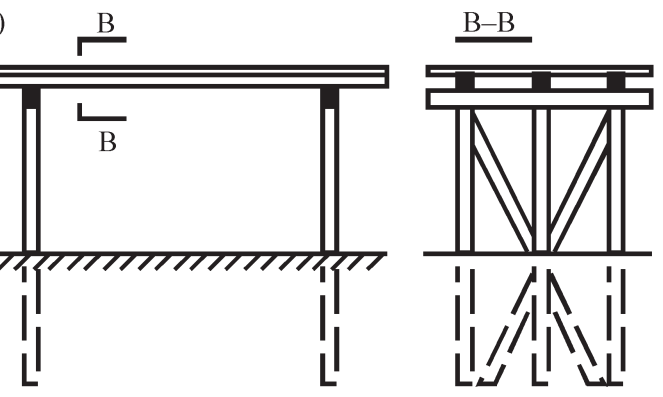

Fig 1. The Klaipeda harbour permeable piers with plain (a) and joisted (b) decks 
made to improve the partial safety factors using the deterministic design method assisted by testing. However, the structural reliability of existing piers can be objectively neither formulated nor assessed by traditional deterministic approaches. It is difficult to give objective and quantitative assessment of the reliability of structures subjected to intermittent action processes and designed according to the deterministic design codes.

Having revised geometrical, mechanical and geotechnical data it is more expedient to predict the structural reliability of piers by the full probabilistic method. The permeable cargo piers likely as bridges may be introduced to geotechnical category 2 [2]. It requires to have quantitative geotechnical data and reliability indices of pier structures. However, the probabilistic reliability assessment of the cargo piers and other harbour work is complicated not only because of uncertainties of structural systems and their action effects, but also due to some methodological and mathematical troubles.

The intention of this paper is to present some new methodological approaches to practical structural reliability assessment of existing permeable cargo piers under more severe behaviour conditions and to call attention of geotechnical, hydraulic and structural engineers to the merits of probability-based approaches.

\section{Account of lateral actions}

\subsection{Lateral actions}

Generally, lateral (horizontal) forces for cargo piers are caused by vessel impacts due to its mooring manoeuvre and berthing vessel or ice loads in piles (Fig 2). Time-variant berthing impacts of cargo vessels and climate actions belong to the persistent design situations despite of short periods of their extreme values which are much shorter than the design

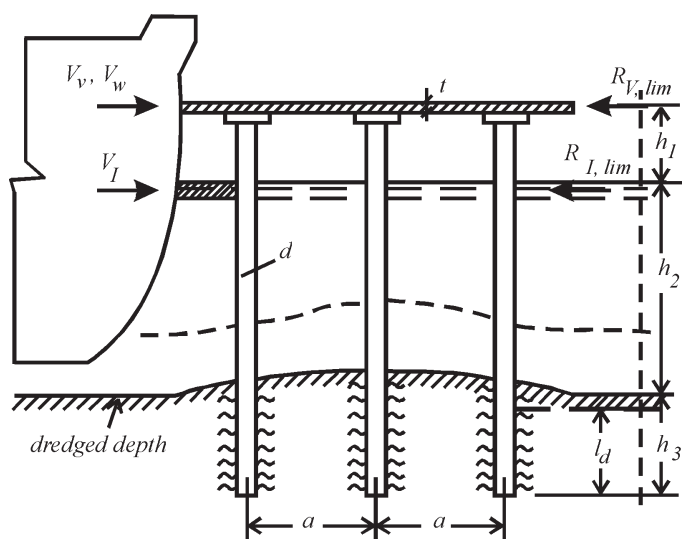

Fig 2. Lateral loads on the cargo pier working life of piers. According to [4] directions cargo piers belong to design working life category 5 the working span of which is $50-100$ years.

All vessels must make their approach transverse to cargo piers with limited velocity. Despite this requirement the value of mooring and berthing impacts fluctuates greatly. Therefore in probabilistic models the lateral impact forces are assumed to be random variables the values of which depend on many factors. The magnitude of berthing loads depends on the vessel dimensions and displacements, its berthing velocity, the fenders and the deformations both of the vessel hull and of the pier system. According to [5] recommendations the characteristic berthing impact forces as their mean values are $V_{v k}=300,600$ and $800 \mathrm{kN}$ when the displacement of vessels is 10000,20000 and 50000 t, respectively.

The characteristic value of the wind force on the moored vessels may be calculated by the formula:

$$
V_{w k}=4,1 k_{t} H L v^{2},
$$

where $k_{t}$ is the conversion factor of wind velocity pressure; $H$ and $L$ are the freeboard height and overall length of vessels [5]. When $k_{t}=18,1 \times 10^{-5}$ $\mathrm{kNs}^{2} / \mathrm{m}^{4}, H=4 \mathrm{~m}, L=150 \mathrm{~m}$, wind velocity $v=20$ and $40 \mathrm{~m} / \mathrm{s}$, the characteristic value $V_{w k}=180$ and $720 \mathrm{kN}$. The characteristic value of the lateral ice load on vertical piles may be expressed as the force:

$$
V_{I k}=0,36 d^{0,5} t_{I}^{1,1} \sigma_{I},
$$

in which $d$ is the width of piles; $t_{I}$ is the thickness of ice; $\sigma_{I} \approx 1,8 \mathrm{MN} / \mathrm{m}^{2}$ is the compressive strength applicable for the fracture of ice. When $d=120 \mathrm{~cm}$, $t_{I}=20$ and $50 \mathrm{~cm}$, value $V_{I k}=192$ and $524 \mathrm{kN}$.

The lateral forces $V_{v k}, V_{w k}$ and $V_{I k}$ are to be multiplied by the factor $\theta_{v}=1,25$ to cover dynamic and other non-ascertainable effects. In any case the representative statistical parameters of actions including their means and variances must be introduced with the values corresponding to the observed in the past actual extreme situations.

\subsection{Concept of irreversible serviceability}

The impact of berthing vessels is to be considered as a free lateral force imposed at a pier deck level the kinetic energy of which is transferred into elastic-plastic deformations of pier members. Besides, inelastic deformations and intensive cracking of concrete members as insensitive cracking of concrete members are indesirable since recurrent lateral forces may destroy structural integrity and ductility of piers. 
In order to guarantee their stability against recurrent berthing actions it is recommended that the horizontal displacement $u$ of pier decks should be not larger than the limit value $u_{\text {lim }}$. Thus, the irreversible serviceability limit state is to be considered.

The irreversible serviceability limit state is the state where some consequences of actions exceeding the specified service requirements will remain when these actions are removed. This state concerns the normal functioning of the piers exposed to recurrent extreme lateral forces and should be based on the criterion concerning the limit displacement value $u_{\text {lim }}$. This criterion is related to pier deck and pile stiffnesses and ductilities. The response on pier systems $R_{v}$ as the serviceability constraint in uncracked behaviour of structures should in principle be regarded as the basic random variable.

Heterogeneous ground media behaviour during lateral actions is an important factor for the irreversible serviceability assessment of pier piles. Galerkin approximation and the stochastic finite element methods can be used for practical applications in calculations of the impact resistance $R_{v}$ [6]. The probabilitybased reliability assessment methodology for the piles under stochastic lateral loads was considered [7]. However, this methodology is practical for the assessment of pile foundations disregarding soil-pile-superstructure interactions.

Horizontal displacements of the Klaipeda pier (Fig 1, a) were determined experimentally and calculated taking into account dangerous lateral forces imposed near expansion joints of the pier (Fig 3). The value $u_{\lim }$ corresponds the impact resistance $R_{v}$ characterizing the beginning of inelastic deformations of this pier system due to concrete cracking. It was modelled by idealizing the spatial frame system with a single degree of freedom when the design value of pile depth is $l_{d}=0,8 h_{3}$ (Fig 2).

The mean value of the impact resistance of pier piles $R_{v m}$ corresponds to the limit ultimate deflection $u_{\lim }$ and the mean of residual concrete resistance in tension $\sigma_{t e s, t m}=\Delta \sigma_{c m}=\sigma_{c t, v} \lim , m_{c c, m}$, where $\sigma_{c t, v_{\lim , m}}$ and $\sigma_{c c, m}$ are the tensile and compressive stresses of piles caused by mean values of the lateral force $V_{\lim , m}$ and the permanent axial force $N_{g m}$.

\subsection{Assessment of irreversible serviceability}

The performance function or irreversible serviceability margin of piers may be written in the form:

$$
M_{V}=\theta_{R} R_{v}-\theta_{v} V
$$

Here $V$ is the resultant lateral force; $R_{v}$ is the impact resistance of the pier the coefficient of variation of which is $\delta R_{v} \approx 0,15 ; \theta_{V}$ and $\theta_{R}$ are the additional variables representing the uncertainties of calculation models which give the values of forces and resistances. They may be presented by their means $\theta_{V m}=1,25[6], \theta_{R m}=1,05-1,30$ [8] and standard deviations $\sigma \theta_{V}=0, \sigma \theta_{R}=0,10$. More exact statistical parameters may be derived from scientific observations and investigations of existing pier systems and their external actions.

The intensity of force $V$ depends on wind velocity, its aerodynamic pressure and the fluctuating pressure induced by the motion of vessels due to wind and waves. The coefficient of variation of this force $\boldsymbol{\delta} V$ depends on the uncertainties of the said-above quantities. According to $[9,10]$ data it is recommended to use the coefficient $\delta V=0,2-0,3$ both in

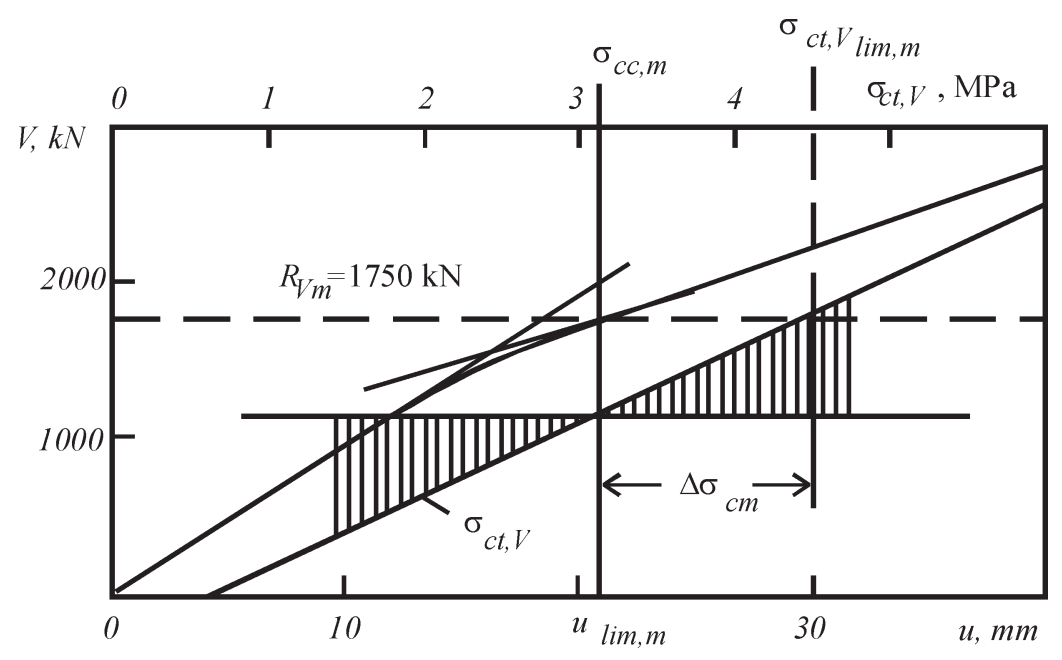

Fig 3. The lateral force $V$ versus the pier deck deflection $u$ and the concrete tensile stress $\sigma_{c t, V}$ 
wind loading and wave-induced action calculations.

The lateral force $\theta_{V} V$ should be modelled as an intermittent rectangular wave renewal process using Gumbel or extreme value Type 1 distribution law. For practical sake the mean value of this force is:

$$
\theta_{v m} V_{m}=\theta_{w m} V_{w k} /\left(1+2,59 \delta V_{w}\right),
$$

where $V_{w k}$ is the value calculated by equation (1).

The survival probability of piers under extreme lateral actions may be calculated by the formula:

$$
\mathbf{P}_{s v}=\mathbf{P}\left\{\theta_{V} V<\theta_{R} R_{V}\right\}=\int_{0}^{\infty} f_{R_{V}}(x) F_{V}(x) d x .
$$

Here $f_{R_{V}}(x)$ is the density function on the impact resistance $\theta_{R} R_{V} ; F_{V}(x)$ is the cumulative distribution function of the lateral force $\theta_{V} V$ which may be expressed as:

$$
F_{V}(x)=\exp \left[-\exp \left(\frac{\theta_{v m} V_{m}-x}{0,7794 \boldsymbol{\sigma}\left(\theta_{V} V\right)}-0,5772\right)\right],
$$

where $\theta_{v m} V_{m}$ is its mean presented by equation (4) and $\boldsymbol{\sigma}\left(\theta_{V} V\right)$ is its standard deviation.

The survival probability $P_{s v}$ may be computed by the numerical integration or Monte Carlo simulation methods. It must be not less than the minimum value $\boldsymbol{P}_{\min }$. The tentative target reliability index related to the irreversible serviceability limit state of piers is $\beta_{\min }=1,5$ [4]. It corresponds to the target survival probability $\boldsymbol{P}_{\min }=0,933$.

\section{Account of gravity actions}

\subsection{Partial factor design}

Gravity axial compressive forces for cargo pier piles are caused by the mass of cranes, permanent $g$ and variable $q$ loads (Fig 4). The permanent actions include the masses of superstructure and piles themselves. As a variable the load is treated as a irregularly distributed cargo. Internal and external bearing capacity of piles are considered. The internal capacity is their structural resistance as reinforced concrete structures. The external capacity is their subsoil resistance as geotechnical supports.

The external capacity of single piles may be expressed as

$$
R_{g r}=A_{b} f_{b}+\sum_{i=1}^{n} A_{s i} f_{s i},
$$

where $A_{b}$ and $A_{s i}$ are the nominal cross-section and surface areas of the pile; $f_{b}$ and $f_{s i}$ are the base (tip) resistance and the ultimate skin friction of soil layers. The values $f_{b}$ and $f_{s i}$ are classificated by the

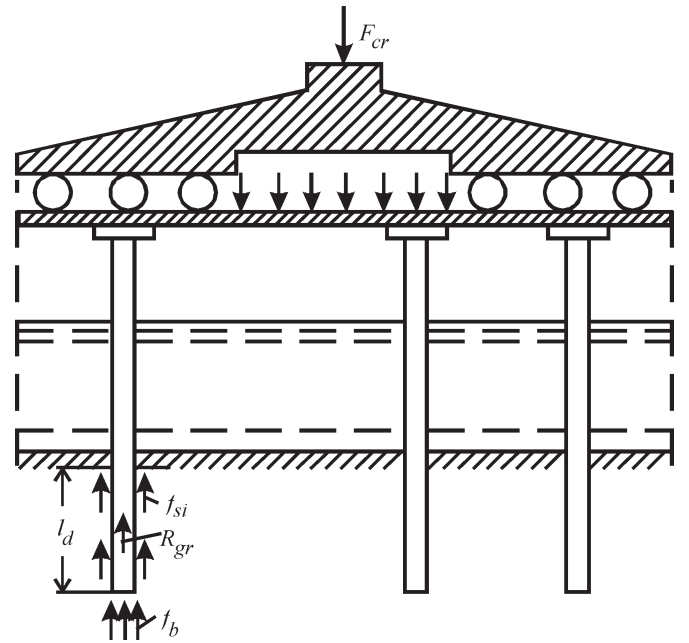

Fig 4. Gravity loads and external resistance of pier piles

characteristic cone penetration resistance $f_{c k}$ and the undrained shear strength $c_{u k}$ for cohesionless and cohesive soils, respectively [11, 12]. Generally, the ultimate skin friction is reached by the settlement of piles $s=1-2 \mathrm{~cm}$ while the tip resistance increases for the settlement $s=10 \mathrm{~cm}$ and more. However, the value $s=2 \mathrm{~cm}$ is the limit settlement for bored piles. is:

The design residual external resistance of pier piles

$$
R_{d}=A_{b} f_{b k} / \gamma_{b}+\sum_{i=1}^{n} A_{s i} f_{s k i} / \gamma_{s},
$$

where $f_{b k}$ and $f_{s k i}$ are the characteristic values of soil parameters; $\gamma_{b}=1,6$ and $\gamma_{s}=1,3$ are the partial factors for bored piles [2]. The design axial compressive force of piles is:

$$
N_{d}=N_{g k} \gamma_{g}+N_{q k} \gamma_{q} \text {, }
$$

where $N_{g k}$ and $N_{q k}$ are the characteristic values of components caused by permanent and variable actions; $\gamma_{g}=1,35$ and $\gamma_{q}=1,5$ are the partial factors for actions [4]. The inequality $N_{d} \leq R_{d}$ demonstrates that the piles may be treated as reliable geotechnical supports.

\subsection{Probability-based design}

For soil resistance $f_{b}$ and $f_{s}$ the lognormal distribution function has commonly been used [13-15]. The coefficients of variation of this resistance are 20-30\% [13] and 10-60\% [14, 16]. The mean and variance of pile external resistance may be presented as follows:

$$
\begin{aligned}
& R_{g r, m}=A_{b} f_{b m}+\sum_{i=1}^{n} A_{s i} f_{s i m}, \\
& \boldsymbol{\sigma}^{2} R_{g r}=A_{b}^{2} \boldsymbol{\sigma}^{2} f_{b}+\sum_{i=1}^{n} A_{s i}^{2} \boldsymbol{\sigma}^{2} f_{s i}+
\end{aligned}
$$




$$
2 \sum_{i=1}^{n} A_{b} A_{s i} \boldsymbol{\sigma} f_{b} \boldsymbol{\sigma} f_{s i} \operatorname{Cov}\left(f_{b}, f_{s i}\right)
$$

where $\boldsymbol{\sigma}^{2} f_{b}, \boldsymbol{\sigma}^{2} f_{s i}$ and $\operatorname{Cov}\left(f_{b}, f_{s i}\right)$ are the variances and covariance of soil parameters $f_{b}$ and $f_{s i}$. The probability distribution of permanent $g$ and variable $q$ actions of cargo piers are also closed to the lognormal one with the coefficients of variation $\boldsymbol{\delta} g=0,1$ and $\boldsymbol{\delta} q=0,3[3,4]$.

The performance function or the safety margin of axially loaded piles can be written in the form:

$$
M_{g r}=\theta_{R} R_{g r}-\theta_{N} N
$$

Here

$$
\theta_{N} N=\theta_{c r} N_{c r}+\theta_{g} N_{g}+\theta_{q} N_{q}
$$

is the random axial force of single piles, where $N_{c r}$ is the crane mass component as the deterministic value; $N_{g}$ and $N_{q}$ are the components caused by permanent $g$ and variable $q$ loads, the coefficients of which are: $\boldsymbol{\delta} g=0,10$ and $\boldsymbol{\delta} q=0,30$. The means and coefficients of variation of the additional variables are: $\theta_{R m}=1,0$ $1,1, \quad \theta_{c r, m}=\theta_{g m}=\theta_{q m} \approx 1$ and $\delta \theta_{R}=0,05-0,10$, $\boldsymbol{\delta} \theta_{c r}=\boldsymbol{\delta} \theta_{g}=\boldsymbol{\delta} \theta_{q} \approx 0,10[8,17]$.

When the probability distribution of the safety margin components obeys the lognormal one, the survival probability of pier piles under gravity actions may be calculated by the analytical method using the formula:

$$
\begin{aligned}
\boldsymbol{P}_{s, g r} & =\int_{0}^{\infty} f_{R_{g r}}(x) F_{N}(x) d x= \\
& \boldsymbol{\Phi}\left\{\frac{\ln \left[\frac{\theta_{R m} R_{g r, m}}{\theta_{N m} N_{m}}\left(\frac{1+\boldsymbol{\delta}^{2}\left(\theta_{N} N\right)}{1+\boldsymbol{\delta}^{2}\left(\theta_{R} R_{g r}\right)}\right)^{1 / 2}\right]}{\left\{\ln \left[\left(1+\boldsymbol{\delta}^{2}\left(\theta_{N} N\right)\right)\left(1+\boldsymbol{\delta}^{2}\left(\theta_{R} R_{g r}\right)\right)\right]\right\}^{1 / 2}}\right\},
\end{aligned}
$$

where $\boldsymbol{\delta}\left(\theta_{R} R_{g r}\right)=\boldsymbol{\sigma}\left(\theta_{R} R_{g r}\right) /\left(\theta_{R m} R_{g r, m}\right)$ and $\boldsymbol{\delta}\left(\theta_{N} N\right)=$ $=\boldsymbol{\sigma}\left(\theta_{N} N\right) /\left(\theta_{N m} N_{m}\right)$ are the coefficients of variation of the external resistance and the axial force of single piles, respectively.

Since the ultimate limit state of cargo piers is considered, the target reliability index $\beta$ for 50 years reference period is $\beta_{\min }=3,3$ [4]. It corresponds to the target survival probability $\boldsymbol{P}_{s, g r, \min }=0,9995$.

\section{Numerical illustration}

The cargo pier of the Klaipeda seaport is exposed to lateral (Fig 2) and gravity (Fig 4) actions, the probability distributions of which are Gumbel and lognormal, respectively [18]. It needs to assess its structural reliability in the dredging waters situation.

\section{Account of lateral actions}

The characteristic value, coefficient of variation and variance of the lateral force $V_{w}$ are: $V_{w k}=820$ $\mathrm{kN}, \boldsymbol{\delta} V_{w}=0,25 ; \boldsymbol{\sigma}^{2} V_{w}=(0,25 \times 820)^{2}=42025(\mathrm{kN})^{2}$. According to equation (4) the mean and variance of force $\theta_{V} V_{V}$ are:

$$
\begin{aligned}
& \theta_{V m} V_{w m}=1,25 \times 820 /(1+2,59 \times 0,25)=622 \mathrm{kN} ; \\
& \boldsymbol{\sigma}^{2}\left(\theta_{V} V_{w}\right)=1,25^{2} \times 42025=102600(\mathrm{kN})^{2} .
\end{aligned}
$$

The mean and variance of impact resistance of the pier is $R_{V m}=1750 \mathrm{kN}$ (Fig 3) and $\boldsymbol{\sigma}^{2} R_{V}=(0,15 \times 1750)^{2}=68900(\mathrm{kN})^{2}$. Therefore, the mean and variance of resistance $\theta_{R} R_{V}$ are:

$\theta_{R m} R_{V m}=1,1 \times 1750=1925 \mathrm{kN}$;

$\boldsymbol{\sigma}^{2}\left(\theta_{R} R_{V}\right)=1,1^{2} \times 68900+1750^{2} \times 0,01=114000(\mathrm{kN})^{2}$.

According to equation (5) the survival probability of the pier under extreme lateral actions is: $\mathbf{P}_{s v}=0,9925>\mathbf{P}_{s v, \min }(=0,933)$.

\section{Account of gravity actions}

The geometrical pile and statistical soil characteristics are: $l_{d}=6,4 \mathrm{~m} ; A_{b m}=0,41 \mathrm{~m}^{2}$;

$$
\begin{aligned}
& A_{s m}=24,1 \mathrm{~m}^{2} ; \boldsymbol{\delta} f_{b}=\boldsymbol{\delta} f_{s}=0,225 \\
& f_{b m}=4,424 \mathrm{MPa} ; f_{s m}=0,177 \mathrm{MPa} \\
& \boldsymbol{\sigma}^{2} f_{b}=(0,225 \times 4,424)^{2}=0,991(\mathrm{MPa})^{2} ; \\
& \boldsymbol{\sigma}^{2} f_{s}=(0,225 \times 0,177)^{2}=0,001586(\mathrm{MPa})^{2} ;
\end{aligned}
$$

$\operatorname{Cov}\left(f_{b}, f_{s}\right)=0,9 \times \sqrt{0,991} \times \sqrt{0,001586}=0,03567(\mathrm{MPa})^{2}$.

Since the values of additional variable characteristics are $\theta_{R m}=1,0$ and $\delta \theta_{R}=0,1$, the mean, variance and coefficient of variation of the external resistance of piles are:

$$
\begin{aligned}
& \theta_{R m} R_{g r m}=0,41 \times 4,424+24,1 \times 0,177=6,079 \mathrm{MN} ; \\
& \boldsymbol{\sigma}^{2} R_{g r}=0,41^{2} \times 0,991+24,1^{2} \times 0,001586+ \\
& (2 \times 0,41 \times 24,1 \times 0,03567)=1,792(\mathrm{MN})^{2} ; \\
& \boldsymbol{\sigma}^{2}\left(\theta_{R} R_{g r}\right)=1,792+6,079^{2} \times 0,01=2,162(\mathrm{MN})^{2} ; \\
& \boldsymbol{\delta}^{2}\left(\theta_{R} R_{g r}\right)=2,162 /(6,079)^{2}=0,05848 .
\end{aligned}
$$

The statistical characteristics of basic and additional variables of the axial force components are: $N_{c r, m}=0,577 \mathrm{MN} ; \quad N_{g m}=N_{g k}=0,579 \mathrm{MN}$; $N_{q m}=N_{q k}=0,909 \mathrm{MN} ; \boldsymbol{\delta} N_{c r}=0 ; \boldsymbol{\delta} N_{g}=0,1 ; \boldsymbol{\delta} N_{q}=$ 0,$3 ; \theta_{c r, m}=\theta_{g m}=\theta_{q m}=1 ; \boldsymbol{\delta} \theta_{c r}=\boldsymbol{\delta} \theta_{g}=\boldsymbol{\delta} \theta_{q}=0,1$. Thus, the means and variances of these components are:

$$
\begin{aligned}
& \boldsymbol{\sigma}^{2}\left(\theta_{c r} N_{c r}\right)=0,577^{2} \times 0,01=0,00333(\mathrm{MN})^{2} \\
& \boldsymbol{\sigma}^{2}\left(\theta_{g} N_{g}\right)=(0,1 \times 0,579)^{2}+0,579^{2} \times 0,01= \\
& 0,00671(\mathrm{MN})^{2}
\end{aligned}
$$


$\boldsymbol{\sigma}^{2}\left(\theta_{q} N_{q}\right)=(0,3 \times 0,909)^{2}+0,909^{2} \times 0,01=$ $0,08262(\mathrm{MN})^{2}$.

Therefore, the mean, variance and coefficient of variation of the axial force are:

$$
\begin{aligned}
& \theta_{N m} N_{m}=0,577+0,579+0,909=2,065 \mathrm{MN} ; \\
& \boldsymbol{\sigma}^{2}\left(\theta_{N} N\right)=0,00333+0,00671+0,08262= \\
& 0,09266(\mathrm{MN})^{2} ;
\end{aligned}
$$$$
\delta^{2}\left(\theta_{N} N\right)=0,09266 / 2,065^{2}=0,02173 \text {. }
$$

According to equation (14) the survival probability of the cargo pier piles under gravity actions is $\mathbf{P}_{s, g r}=0,999927>0,9995$.

According to the results of probability-based analysis the structural safety of the cargo pier is sufficient.

\section{Conclusions}

The structural reliability of cargo pier piles greatly depends on the uncertainties of soil resistance parameters and variable lateral (horizontal) and gravity actions. Therefore, it is difficult and sometimes impossible to ensure and predict the sufficient external reliability of pier piles designed according to Eurocode 7 recommendations. The presented probability-based methodological approaches for the assessment of the structural reliability of new and existing piers may play a significant role reducing the likelihood of unexpected failures of habour structures.

A quite realistic methodological way is presented to reveal the performance criteria of existing cargo pier piles after the dredging of harbour waters and to assess their reliability by the probability-based method. The survival probability analysis of the piles is based on their irreversible serviceability and safety margin criteria when the action effects are caused by lateral and gravity forces, respectively.

The results of this paper show that the probability-based assessment and the prediction of the reliability of harbour cargo piers are not complicated. Therefore, it is high time for probabilistic principles and approaches to be established in geotechnical and hydraulic design and construction practice.

\section{References}

1. Mori, V. \& Ellingwood, B. Reliability based service-life assessment of aging concrete structures. Journal of Structural Engineering, ASCE, Vol 119, No 5, 1993, p. $1600-1621$.
2. EN 1997. Eurocode 7, Part 1. Geotechnical design, general rules, Brussels, CEN, 2003.

3. ISO 2394. General principles on reliability for structures. Switzerland, 1998.

4. EN 1990. Eurocode-Basic of structural design. Brussels, CEN, 2002.

5. EAU 1996. Harbours and Waterways. Recommen-dations of the Committee for Waterfront Structures. Berlin: Ernst \& Sohn, 2000.

6. Suzuki, M. \& Takada, T. Response of pile embedded in stochastic ground media. Probabilistic Mechanics and Structural Reliability, ASCE, USA, 1996, p. 612-615.

7. Eloseily, K. H., Ayyub, B.M. \& Patev, R. Reliability assessment of pile groups in sands. Journal of Structural Engineering, Vol 128, No 10, 2002, p. 1346-1353.

8. JCSS. Probabilistic model code, 12th draft, 2000.

9. ISO 4354. Wind action on structures, Switzerland, 1997.

10. Atua, K.; Assakkai, J. \& Ayyub, B. M. Statistical characteristics of strength and load random variables of ship structures. Probabilistic Mechanics and Structural Reliability, ASCE, USA, 1996, p. 106-109.

11. Mets, M. The bearing capacity of a single pile. In: Baltic Geotechnics. Ed. L. Furmonavicius, Balkema, 1995, p. 109-112.

12. Katzenbach, R. \& Moormann, Chr. Design of Axially Loaded Piles and Pile Groups-German Practice. Design of Axially Loaded Piles-European Practice. Roterdam: Balkema, 1997, p. 177-201.

13. König, G.; Soukhov \& D., Ahner, C. Reliability of piled raft foundations. In: Safety, Risk, Reliability-Trends in Engineering. Malta, 2001, p. 659-664.

14. Phoon, K. K. \& Kulhawy, F. H. EPRJ study on LRFD and MRFD for transmission line structure. In: Foundation design codes and soil investigation in view of international harmonization and performance. Swetz \& Zeitlinger, Lisse, 2002, p. 253-261.

15. Zhang, L.; Tang, W. H. \& Zhang, L. Reliability-based design of large-diameter bored piles in Hong Kong Part 1: Evaluation of design methods. In: Foundation design codes and soil investigation in view of international harmonization and performance. Swetz \& Zeitlinger, Lisse, 2002, p. 263-271.

16. Jardine, R. J.; Standing, J. R.; Bond, A. J. \& Parker E. A. Competition to access the reliability of pile prediction methods. In: Proceedings of the Fifteenth International Conference on the Soil Mechanics and Geotechnical Engineering, V. 2. Istambul, 2001, p. 911914.

17. Hong, H. P. \& Lind, N. C. Approximate reliability analysis using normal polynomial and simulation results. Structural safety, Vol 18, No 4, 1996, p. 329-339.

18. Kudzys, A.; Vaicekauskas, L. J. Investigation of doublesuperstructure bridges of the Klaipeda sea port. Transport, Vol XIII, No 4, 1998, p. 170-174. 